Vol. 6, No. 2, 2020

\author{
Volodymyr Gurey ${ }^{1}$, Vitaliy Korendiy ${ }^{2}$, Ihor Kuzio ${ }^{3}$ \\ ${ }^{1}$ Department of Mechanics and Automation Engineering, Lviv Polytechnic National University, Ukraine, Lviv, \\ S. Bandery Street 12, E-mail: Volodymyr.I.Hurei@lpnu.ua, ORCID 0000-0002-5117-6802 \\ ${ }^{2}$ Department of Mechanics and Automation Engineering, Lviv Polytechnic National University, Ukraine, Lviv, \\ S. Bandery Street 12, E-mail: Vitalii.M.Korendii@1pnu.ua, ORCID 0000-0002-6025-3013 \\ ${ }^{3}$ Department of Mechanics and Automation Engineering, Lviv Polytechnic National University, Ukraine, Lviv, \\ S. Bandery Street 12, E-mail: Ihor.V.Kuzo@lpnu.ua, ORCID 0000-0001-9271-6505
}

\title{
SIMULATION MODELLING OF DYNAMIC PROCESSES DUE DISCONTINUOUS FRICTIONAL TREATMENT OF THE FLAT SURFACES
}

Received: April 22, 2020 / Revised: June 30, 2020 / Accepted: September 30, 2020

(C) Gurey V., Korendiy V., Kuzio I., 2020

\begin{abstract}
Friction treatment refers to surface strengthening (hardening) methods using highly concentrated energy sources. In the course of this processing in the surface layers of the processed surfaces of parts the strengthened layer with nanocrystalline structure is formed. The formed layer has specific physical, mechanical, chemical properties, as well as improved performance properties, which are significantly different from the base metal. A highly concentrated energy source is formed in the contact area of the tool-part due to the high-speed friction $(60-90 \mathrm{~m} / \mathrm{s})$ of the tool on the treatment surface. Frictional treatment of flat parts according to the kinematics of the process is similar to grinding. The strengthening process was carried out on an upgraded surface grinder. The tool is a metal disk made of stainless-steel. Transverse grooves are formed on the working surface of the tool to intensify the process of forming a strengthened (reinforced) layer with a nanocrystalline structure. The grooves form additional shock loads in the contact area of the tool-treatment surface of the part. These shock loads increase the shear deformation of the metal of the parts' surface during treatment, which affects into formation the quality parameters of the parts' surface and surface layer. To study the friction treatment process, the calculation scheme of the elastic system of the machine was developed. A simulation model for the study of dynamic processes that take place during the friction treatment of flat surfaces was built. This model gives possibility to determine the displacements and velocities of the machine table on which the part is fixed and the tool, and to determine their mutual displacement and also calculate the reaction of the machine table.
\end{abstract}

Keywords: friction treatment, nanocrystalline layer, simulation model, surface hardening.

\section{Introduction}

The problem of efficiency of machines and mechanisms can be solved by technological quality assurance of the surface layer. This is due to the fact that the connection of machine parts takes place on working surfaces and their destruction usually begins with the surface. The performance of machine parts is significantly affected by the quality of the contact surfaces and the surface layer [1], [2]. The quality of surfaces is determined by geometric parameters, namely the deviations of the profile, waviness, roughness, load capacity of the profile, as well as the relative position of microroughnesses on the contact surfaces. The characteristics of the surface layer are determined by its microhardness, texture, structure, grain size, phase and chemical compositions, residual stresses, the density of defects in the crystal structure, and so on [3], [4]. All these parameters and characteristics depend on methods and technologies of processing of working surfaces of machine parts [5]. Strengthening the working surfaces of machine parts increases their wear resistance and fatigue strength. 


\section{Volodymyr Gurey, Vitaliy Korendiy, Ihor Kuzio}

One of the methods of surface strengthening (hardening) of machine parts is friction treatment, which refers to methods of strengthening (hardening) using highly concentrated energy sources. The action of such energy sources on the treated surfaces leads to high-speed heating of local volumes of metal of the surface layer to temperatures above the phase transformation point. After escaping the energy source, the heated metal is cooled at high speed. In the contact area of the tool-part also undergoes shear deformation of the surface layer during the friction of the tool on the treated surface. Under the action of extreme conditions of heating and cooling, a strengthened (reinforced) surface layer with a nanocrystalline structure is formed [6]. The obtained strengthened layer has specific physical, mechanical, chemical and operational characteristics, which differ significantly from the characteristics of the base metal. A highly concentrated energy source in the contact area of the tool-part occurs due to the high-speed friction of the tool on the treated surface. The formation of a strengthened layer with a nanocrystalline structure occurs in the process of high-speed heating and subsequent high-speed cooling of the metal of the contact zone of the tool-part. Grinding the grains of surface layer's structure of metal is possible during its intensive plastic deformation. In the process of machining to improve the quality of the treated surface try to reduce the impact load [7].

But, in our case, to intensify the process of forming a strengthened layer with a nanocrystalline structure in the contact area of the tool-part additionally created shock loads. The formation of quality parameters of the treated surface is significantly influenced by the dynamic processes that occur in the contact area of the tool-part. After such intensive processing in the surface layers of machine parts a white strengthened layer with a nanocrystalline structure is formed. The strengthened layer has much higher microhardness, modified phase, structural and chemical compositions, ground grain compared to the metal of the main structure. Residual compressive stresses are formed in the surface layer near the surface, which significantly affect and improve performance. Increases wear resistance at various types of friction, resistance to fatigue and corrosion-fatigue destruction, etc. Studies of friction treatment were carried out based on the study of the formation of the strengthened layer, its characteristics, the impact of the strengthened layer on durability. At the same time, the dynamic processes that occur in the process of friction treatment have not been studied.

\section{Main Material Presentation}

Purpose of work: investigate the influence of friction treatment parameters to the dynamic characteristics of the strengthening process the flat machine parts' surfaces.

Friction treatment is similar to grinding in terms of performance and kinematics of the process. For its realization flat grinding machines (for strengthening of flat surfaces) and circular grinding machines or specially developed equipment (for strengthening of surfaces of bodies of rotation) are used. Instead of an abrasive wheel the metal tool disk made of stainless steel is installed. The overall and fixing dimensions of the metal tool correspond to the dimensions of the grinding wheel used on this machine. For the formation in the contact area of the tool-treated surface of the concentrated heat flow requires a linear velocity on the working surface of the tool $60-90 \mathrm{~m} / \mathrm{s}$. To ensure the required speed of the tool, very important is to upgrade the main drive unit of the grinding wheel, other functional displacements of the machine remain unchanged.

Friction treatment of flat surfaces was performed on an upgraded flat grinder (Knuth, German) model HFS 3063 VS. Installed an electric motor with a higher speed. A test calculation of the spindle bearings when working with higher speeds and higher loads was made. The outer diameter of the tool is $360 \mathrm{~mm}$, the width of its working part is $8-10 \mathrm{~mm}$. A metal disk was installed on the face-plate used on this machine. Before installing the face-plate with a metal disk on the machine, its static balancing was performed.

During the friction treatment, a high-speed friction of the tool on the treatment surface of the part takes place in the contact area of the tool-part. In the contact zone there is an intense concentrated source of thermal energy, as well as shear deformation of the metal surface layer. To increase the thickness of the strengthened layer, as well as grinding the grain of its structure in the contact zone, the additional source of shock load was created by the applying transverse grooves on the working surface of the tool. The working part of the tool is discontinuous, i.e., the smooth part and a groove alternate. The width of the groove is 
selected from the condition of guaranteed complete escaping from the contact of the tool's working surface with the treated surface. The width of the groove was equal $2-4 \mathrm{~mm}$. During friction treatment the tool is pressed with force of 400-1200 $\mathrm{N}$ to the treatment surface. Under its action in the contact zone there is a radial component of the force of interaction. Due to the rotation of the tool in the contact zone there is a tangential component of the interaction force, which will determine the magnitude of the heat flux. During the passage of the groove over the contact area of the tool-part, the contact area is unloaded and at this point in time the normal and tangential components of the interaction force are zero. The heat source is stopped. During the contact of the next smooth part of the tool is the new shock load in the contact zone, and then high-speed friction of the smooth part of the tool on the treated surface. The action of the intense thermal energy source is restored in the contact zone. The contact zone on the treated surface receives the pulsed action of thermal energy, shear deformation and additional shock load. The frequency of shock loads depends on the number of grooves on the tool's working part. All these processes contribute to the formation of a strengthened white layer with a nanocrystalline structure of greater thickness with increased hardness and grain grinding than after processing with a tool with a smooth working surface.

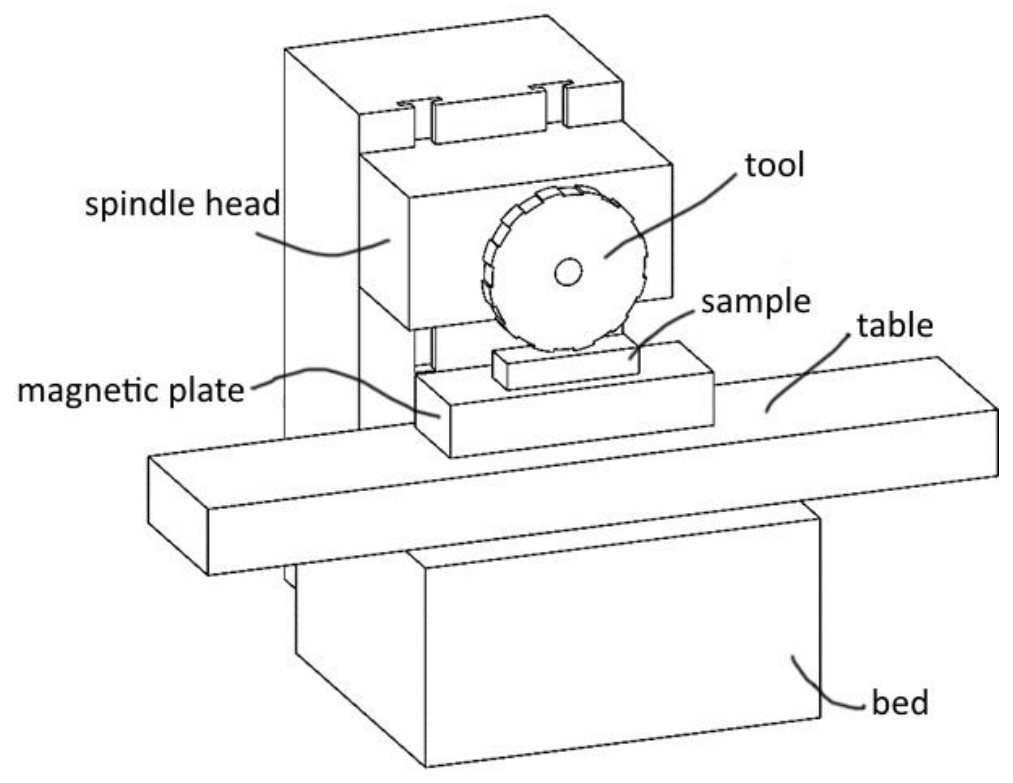

Fig. 1. The model of machine units of flat grinding machine

A mathematical model of the elastic system of a flat grinding machine for friction treatment of flat surfaces was developed earlier and published in [8]. Based on the constructed mathematical model, we develop the simulation model of process of frictional treatment of flat surfaces. The designed scheme of the flat grinding machine which is used for frictional treatment of flat surfaces is developed, and is presented in Fig. 2. For convenience of the analysis of oscillatory processes we will bring the given designed scheme to two-mass. In this scheme, the mass of the spindle head (unit) will be reduced to the mass of the tool, the same steps will be performed with the appropriate stiffness and damping. The interaction (impact) between the part and the tool (vertical) is modelled by contact stiffness and energy damping of local elastic-plastic deformation of the part's surface. The machine's mechanical system has four degrees of freedom: displacements of a spindle and part with a table in horizontal and vertical planes. As generalized coordinates we accept the corresponding linear displacements of a spindle with tool and a table with a part. Differential equations that describe the motion of the system are based on Lagrange's equations of the second kind [9].

That should be as follows:

$$
\frac{d}{d t}\left(\frac{\partial E_{k}}{\partial \underset{\perp}{\alpha}}\right)-\frac{\partial E_{k}}{\partial x_{i}}+\frac{\partial E_{p}}{\partial x_{i}}+\frac{\partial \Phi_{d}}{\partial \underset{\perp}{\alpha}}=Q_{x_{i}}, \quad i=1 \ldots 4,
$$




\section{Volodymyr Gurey, Vitaliy Korendiy, Ihor Kuzio}

where $E_{k}$ - kinetic energy of the system; $E_{p}$ - potential energy of the system; $\Phi_{d}$ - function of the energy dissipation in the system (Rayleigh dissipation function); $Q_{x_{i}}$ - generalized forces corresponding to the chosen generalized coordinates $x_{i}$.

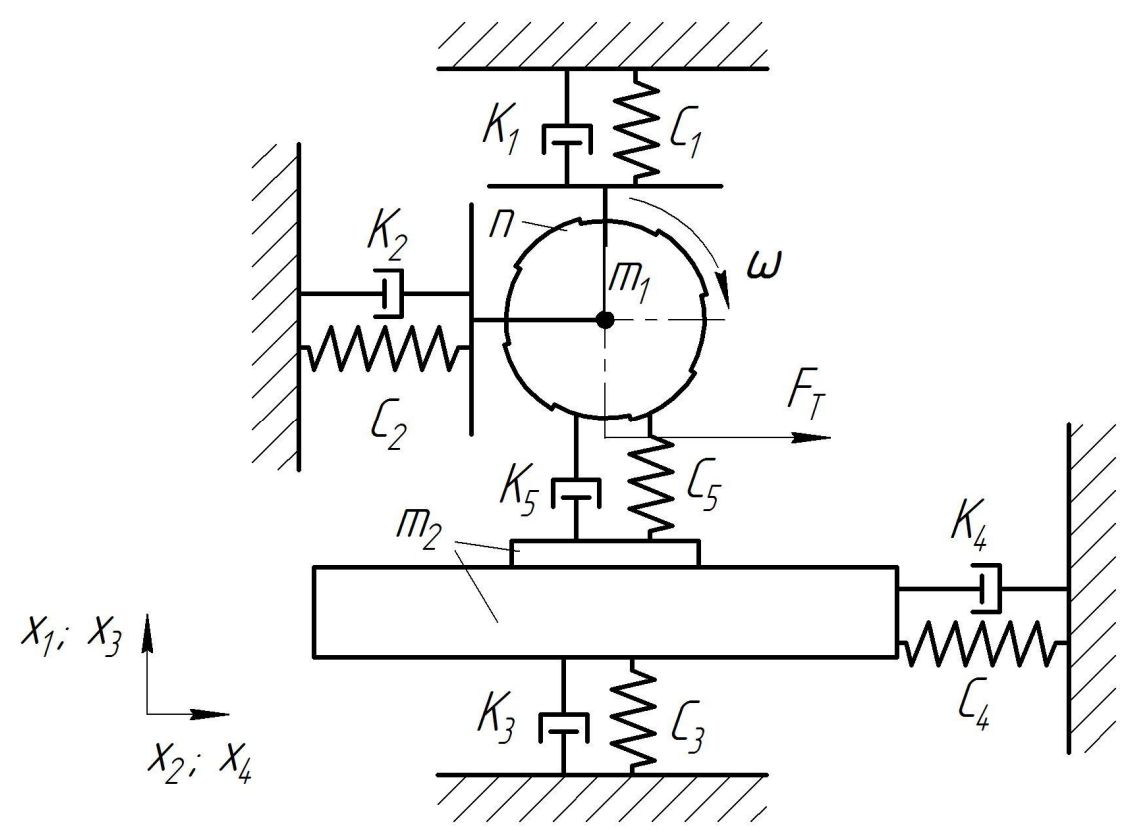

Fig. 2. Design scheme of discontinuous friction treatment

The disturbance that occurs in the contact area of the tool-part has a shock character and for this oscillating scheme is formed based on the shape of the tool's working surface (Fig. 3) and the press force the tool to the part (workpiece). This tool, with an outer diameter $(D)$, has transverse grooves $(n)$ on the working part, and is mounted on a flat grinding machine. Its diametrical dimensions must correspond to the overall dimensions of the grinding wheel used on this machine.

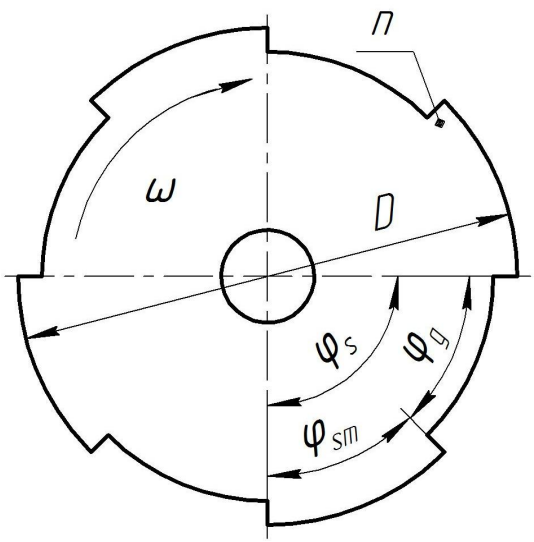

a

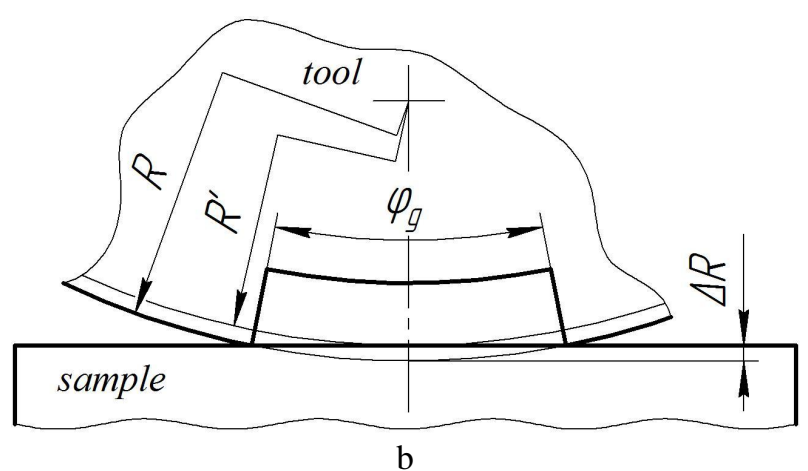

Fig. 3. Geometric parameters of the tool for frictional processing:

a) sketch of the tool: b) geometry of the groove

In this simulation model, the force of press the tool to the part is proposed to define implicitly, i.e., using the relative displacement of the spindle head to the machine table $(\Delta x)$. That is to say, setting some displacement $\Delta x$, the pressing force is formed taking into account the total stiffness of the oscillating circuit of the machine. This statement was chosen based on the fact that most machines are not able to measure the components of the force during the machining process, but the value of vertical displacement is established. The normal force that can be during processing is pre-determined by the calibration dynamometer. 


\section{Simulation Modelling of Dynamic Processes Due Discontinuous Frictional Treatment of the ...}

To record the condition of the pressing force of the tool to a part that is not constant during of the treatment, it is necessary to take into account the condition when the smooth working part is in contact, and as well as when there is a groove in the contact area. When the smooth part of the tool is in contact with the treated surface, we assume that the force is constant, when the smooth part of the tool ends and the groove begins to enter to the contact zone, the pressing force begins to decrease and goes to zero. And also, it is necessary to consider the parameter $\Delta R$ which depends on quantity of grooves and a parity size of a groove to a smooth part when a groove stays over part. That is, if $\Delta x>\Delta R$ the tool has a constant contact with the part, but this contact occurs before or after the contact zone (see Fig. 3b). Therefore, the condition of forming the pressing force is divided into three cases, the first - the contact of the smooth part of the tool (constant contact), the second - the beginning or end of the groove with checking $\Delta R$, the third - no pressing force. Analytical dependences for establishing appropriate generalized forces $Q_{x_{i}}$ are as follows:

$$
\begin{aligned}
& Q_{x_{1}}=Q_{x_{3}}=\left\{\begin{array}{l}
\Delta x \cdot \frac{c_{1} \cdot c_{3} \cdot c_{5}}{c_{3} \cdot c_{5}+c_{1} \cdot c_{5}+c_{1} \cdot c_{3}}, \quad \omega t=\left(0 \ldots \varphi_{g}\right)+\frac{2 \pi}{n} \cdot j ; \\
\left\{\begin{array}{l}
(\Delta x-(R-R \cdot \cos (\omega t))) \cdot \frac{c_{1} \cdot c_{3} \cdot c_{5}}{c_{3} \cdot c_{5}+c_{1} \cdot c_{5}+c_{1} \cdot c_{3}}, \mid \omega t=\left(\varphi_{g} \ldots \varphi_{s}\right)+\frac{2 \pi}{n} \cdot j, \\
0,(\Delta x-(R-R \cdot \cos (\omega t)))<0,
\end{array}\right.
\end{array}\right. \\
& j=0,1,2, \ldots n-1, \\
& Q_{x_{2}}=-Q_{x_{4}}=F_{T}=Q_{x_{1}} \cdot f=Q_{x_{3}} \cdot f
\end{aligned}
$$

The magnitude of the disturbance, which depends on the geometry of the tool (see Fig. 3):

$$
\Delta R=R-R^{\prime}=R-R \cdot \cos \left(\frac{\varphi_{g}-\varphi_{s}}{2}\right)=R\left(1-\cos \left(\frac{\pi}{n}(1-k)\right),\right.
$$

Therefore, according to formula (1), the differential equations of the friction treatment process have the following form:

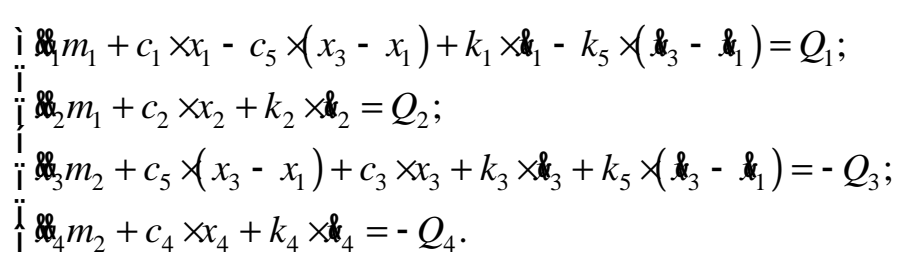

where $m_{1}$ - weight of the machine's spindle head with weight of the tool; $m_{2}=m_{p}+m_{t b}$ - weight of the part and weight of the machine's table; $m_{p}$ - weight of the part; $m_{t b}$ - weight of the machine's table; $c_{1}-$ stiffness of the machine's spindle and spindle head in vertical direction; $c_{2}-$ stiffness of the machine's spindle and spindle head in horizontal direction; $c_{3}$ - stiffness of the machine's table in vertical direction; $c_{4}$ - stiffness of the machine's table spindle in horizontal direction; $c_{5}$ - contact stiffness between the tool and part; $f$-coefficient of friction between tool and part, $n$ - number of grooves that formed on the working part of the tool; $k_{1}$ - vertical damping coefficient of spindle and spindle head; $k_{2}$ - horizontal damping coefficient of spindle and spindle head; $k_{3}$ - vertical damping factor of the machine's table; $k_{4}-$ horizontal damping factor of the machine's table; $k_{5}$ - damping coefficient between tool and part.

The weight of the machine spindle head with the weight of the tool we will calculate with the following expression:

$$
\begin{gathered}
\frac{1}{m_{1}}=\frac{1}{m_{t l}}+\frac{1}{m_{s p . h d .}} ; \\
\frac{1}{c_{1}}=\frac{1}{c_{s p . h d . v}}+\frac{1}{c_{s . v}} ; \quad \frac{1}{k_{1}}=\frac{1}{k_{s p . h d . v}}+\frac{1}{k_{s . v}} ;
\end{gathered}
$$




$$
\frac{1}{c_{2}}=\frac{1}{c_{s p . h d . h}}+\frac{1}{c_{s . h}} ; \quad \frac{1}{k_{2}}=\frac{1}{k_{s p . h d . h}}+\frac{1}{k_{s . h}},
$$

where $m_{t l}$ - weight of the tool; $m_{s p . h d}$. - weight of the spindle head; $c_{s p . h d . v}$ - stiffness of the machine's spindle head in vertical direction; $c_{s . v}$ - radial stiffness of the machine's spindle in vertical direction in vertical direction; $c_{s p . h d . h}$ - stiffness of the machine's spindle head in horizontal direction; $c_{s . h}$ - stiffness of the machine's spindle in vertical direction in horizontal direction; $k_{s p . h d . v}$ - vertical damping coefficient of spindle head; $k_{s . v}$ - vertical damping coefficient of spindle; $k_{s p . h d . h}$ - horizontal damping coefficient of spindle head; $k_{s . h}$ - horizontal damping coefficient of spindle.

The interaction (impact) between the part and the tool (vertical) is modelled by contact stiffness and energy damping of the local elastic-plastic deformation of the part's surface [10]. That is, it is necessary to provide an additional moment when the displacement of the tool will occur in the opposite direction from the displacement of the part and there will be a complete loss of contact.

$$
\text { if }\left(x_{1}-x_{3}\right)>0 \rightarrow c_{5}=0 ; \quad k_{5}=0 .
$$

Simulation of the mathematical model will be performed using the software Matlab-Simulink. The block-diagram of this model is presented in Fig.4. It consists of 6 sub-blocks, namely: Rotation and Power Generator, Contact Check, Displacement X1, Displacement X2, Displacement X3, Displacement X4.

Simulations of vertical $\left(\mathrm{x}_{1}\right)$ and horizontal $\left(\mathrm{x}_{2}\right)$ displacements according to the system of equations (5) are presented in sub-block "X1" (Fig. 5) and in sub-block "X2" (Fig. 6), accordingly.

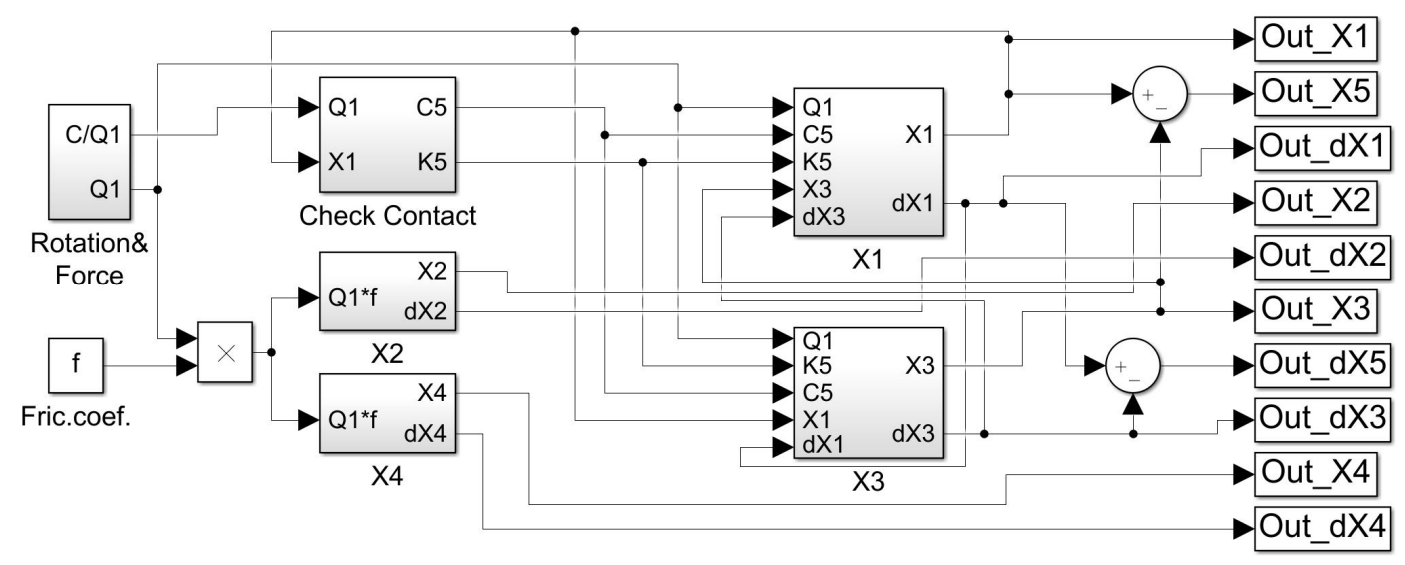

Fig. 4. The block-diagram of simulation model

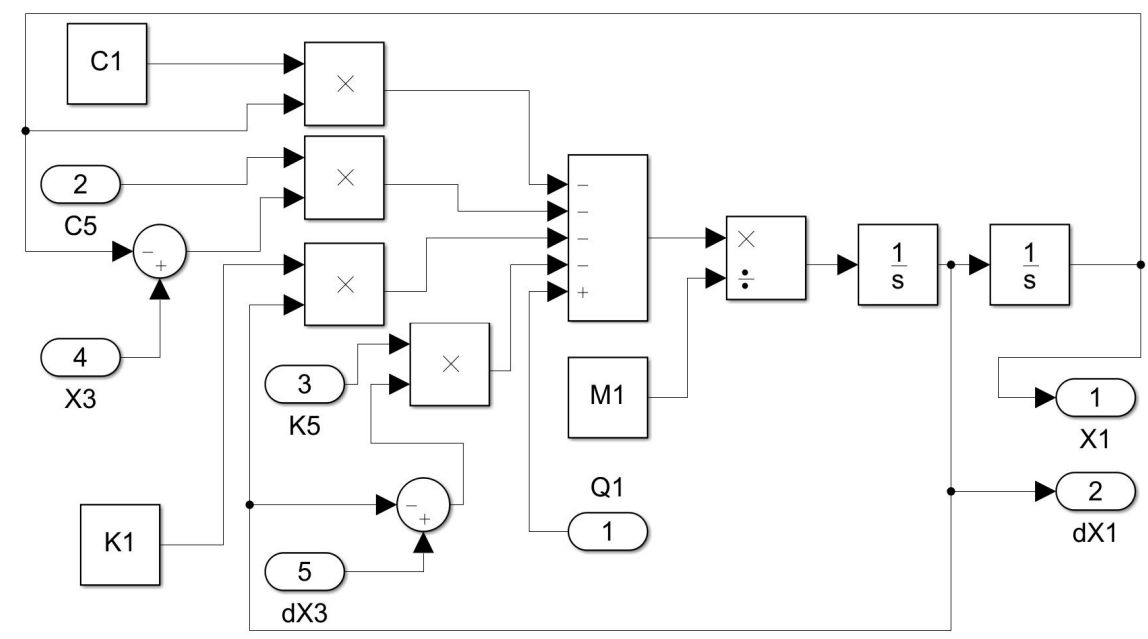

Fig. 5. Sub-block "X1" 


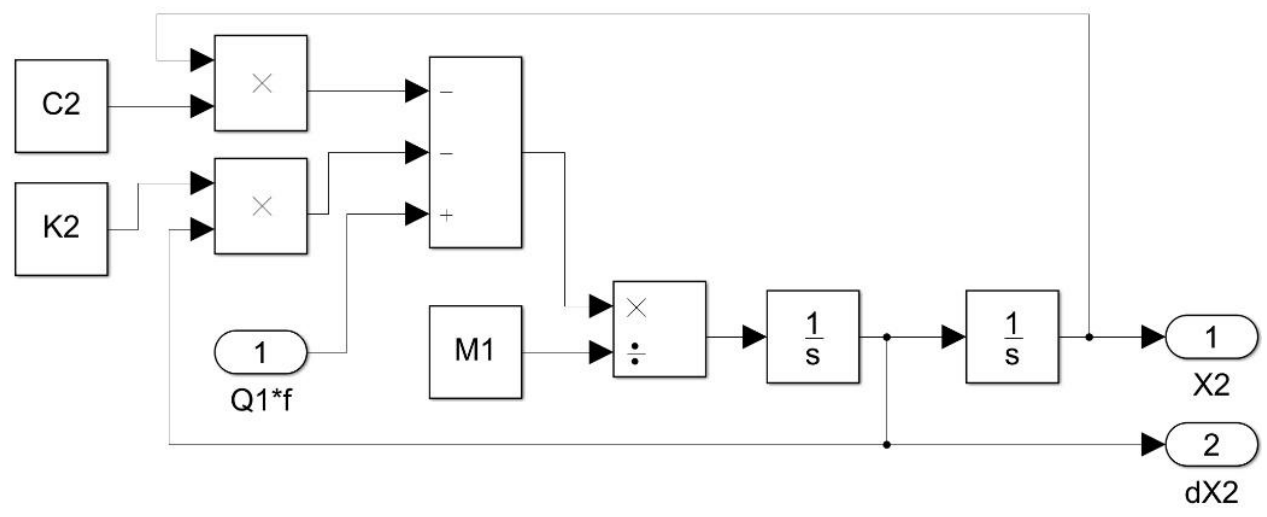

Fig. 6. Sub-block "X2"

The developed model of the machine's elastic system allows to define vertical and horizontal displacements of the part and the tool; velocity of vertical and horizontal displacements of the part and the tool; the value of horizontal and vertical mutual displacement between the part and the tool; the reaction of the machine's table and calculate the calculate the reaction of the table.

The model was tested for adequacy with the following parameters: the number of grooves $n=4$, the angular value of the action of the smooth part $\varphi_{s m}=\pi / 4$; the angular value of the action of the groove $\varphi_{g}=\pi / 4$, i.e. the angular value of the segment is equal $\varphi_{s}=\pi / 2$; the pressing force of the tool to the part is equal $F=500 \mathrm{H}$; tool diameter $D=260 \mathrm{~mm}$; angular spindle speed $\omega=100 \mathrm{rad} / \mathrm{s}$.

During the rotation of the tool, the angle of its rotation is $0 \ldots 2 \pi$ per revolution. At the next rotation of the tool, it is necessary that the angle of rotation was similar to the first angle, i.e., started from zero. Therefore, the repeater signal generator unit was selected. Two model rotations of the tool are selected for modelling (Fig. 7). When plotting the simulation of rotation and action of the smooth part of the tool, we can place "probes" at points of intersection of the corresponding lines and make sure that the proposed operator simulates the rotation good, and as well as determine the time of starting the contact and escaping from contact the smooth part of the tool.

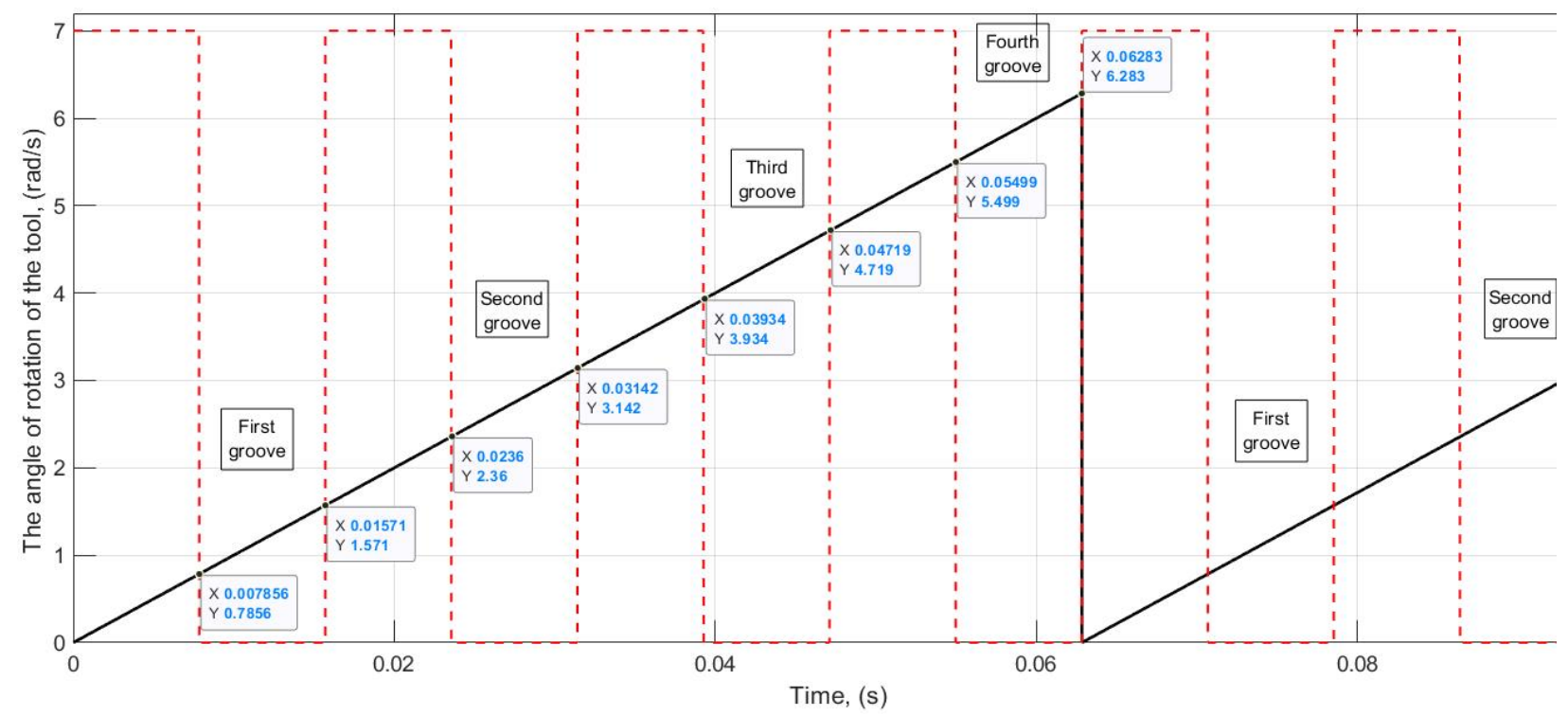

Fig. 7. Simulation of tool rotation

First of all, we will check the unit that controls the geometry of the disk, it's means check the contact conditions of the smooth part of the disk and the groove. The beginning of the groove (unloading) occurs when the $\omega t=\pi / 4(t=0.007854 \mathrm{~s})$ at that time press force decreases to zero (Fig. 8). The end of 


\section{Volodymyr Gurey, Vitaliy Korendiy, Ihor Kuzio}

the action of the groove ends at $\omega t=\pi / 2(t=0.01571 \mathrm{~s})$, so the press force increases from zero to its initial value (see Fig. 8). Therefore, the unit that controls the force works well.

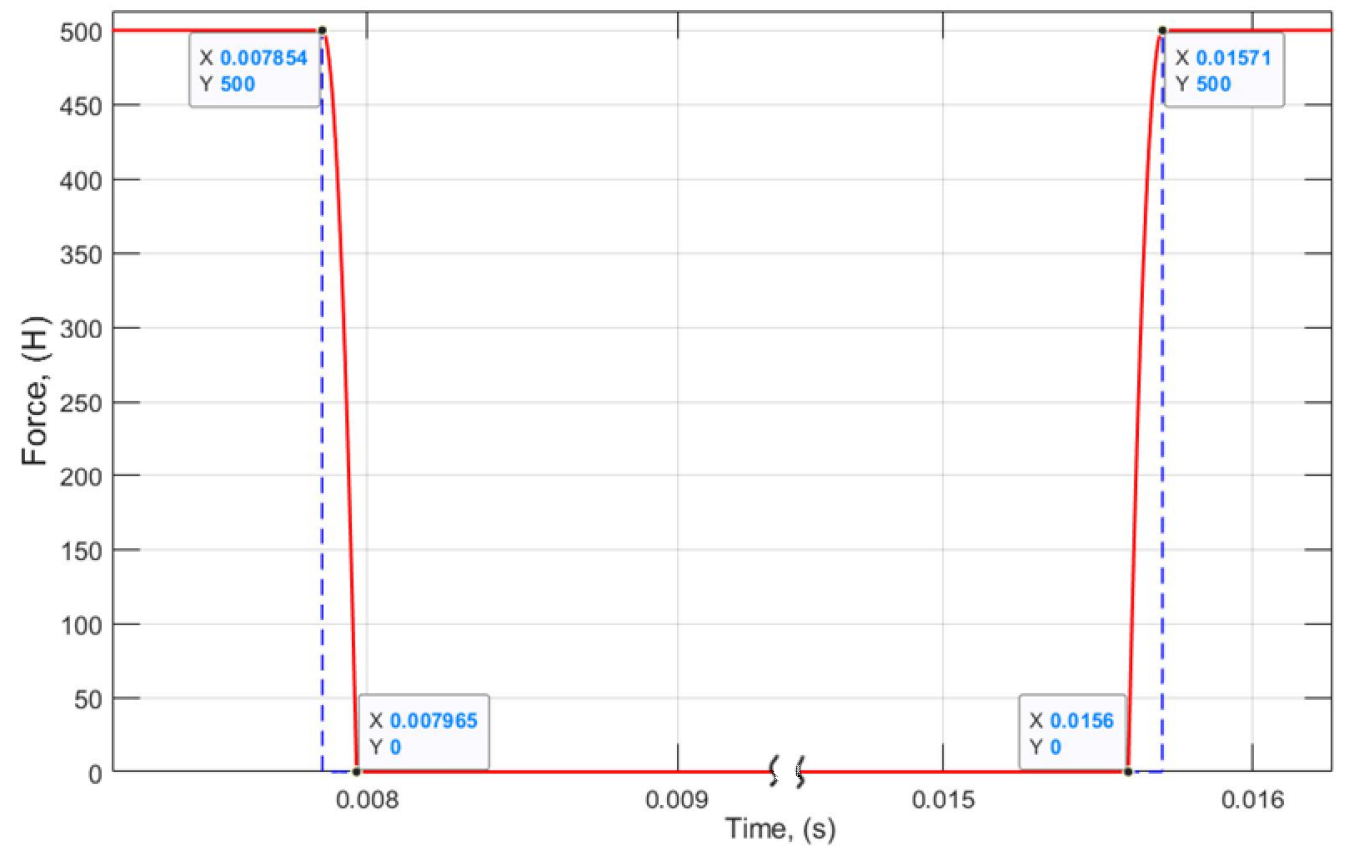

Fig. 8. The force that formed by tool (smooth part and groove).

Numerical solutions are presented in Fig. 9. During the first zone of action of the smooth part of tool's rotation ( $\omega t=0 \mathrm{~K} \pi / 4, t=0 \mathrm{~K} 0.07854 \mathrm{~s}$ ) the spindle of the machine has positive displacement by the initial press force of the tool to the part (Fig. 9a). During the first zone of the smooth part of the tool's rotation, the part, which is fixed on the magnetic plate, will receive a negative displacement from the action of the initial press force of the tool to the part (Fig. 9b). In the second zone when passage the groove $(\omega t=\pi / 4 \mathrm{~K} \pi / 2, t=0.007854 \mathrm{~K} 0.01571 \mathrm{~s})$ there is an unloading of a contact zone. So, when no-force of interaction the spindle returns to initial position (displacement vertically downwards). In this case, there are damped oscillations that dampen relative to zero. In the absence of force of interaction, the part which is fixed on a magnetic plate, returns to initial position (displacement vertically upwards). The part receives damped oscillations that attenuate relative about zero.

In the phase close to $\omega t=\pi / 2(t=0.01571 \mathrm{~s})$ of the tool's rotates, there is an impact that formed by a contact of the following smooth surface with the treatment part, and as result is the positive displacement of the machine spindle and a negative displacement of the part with a distinct transition process, which is also oscillating. The mutual displacement of the tool and the part is calculated by the difference between the displacement of the spindle and the tool (Fig. 9c). At the end of the smooth part, i.e., rotating the tool at the angle $\omega t=\pi / 4$ is a gradual unloading of the contact zone with a smooth transition from $500 \mathrm{~N}$ to zero. And when approaching the next smooth part is a gradual loading of the contact zone and turning the tool at an angle $\omega t=\pi / 2$ the pressing force is $500 \mathrm{~N}$.

The velocity of mutual movement of the part and the tool is shown in the Fig.10.

The interaction force between part and tool is shown in the Fig. 11. Modelling of this process begins with the smooth part, when the smooth part of the interaction force is equal to the press force $(500 \mathrm{~N})$. When the groove zone begins, there is no press force, the oscillations are damped relative to zero. When a new smooth part comes into contact, the amplitude of the interaction force is almost equal to twice press force and changes relative near the value of press force.

Based on the research, we can conclude that the developed simulation model is adequate and really describes the physical process of processing, as well as the established nature of the displacement of the part and tool. 
Simulation Modelling of Dynamic Processes Due Discontinuous Frictional Treatment of the ...
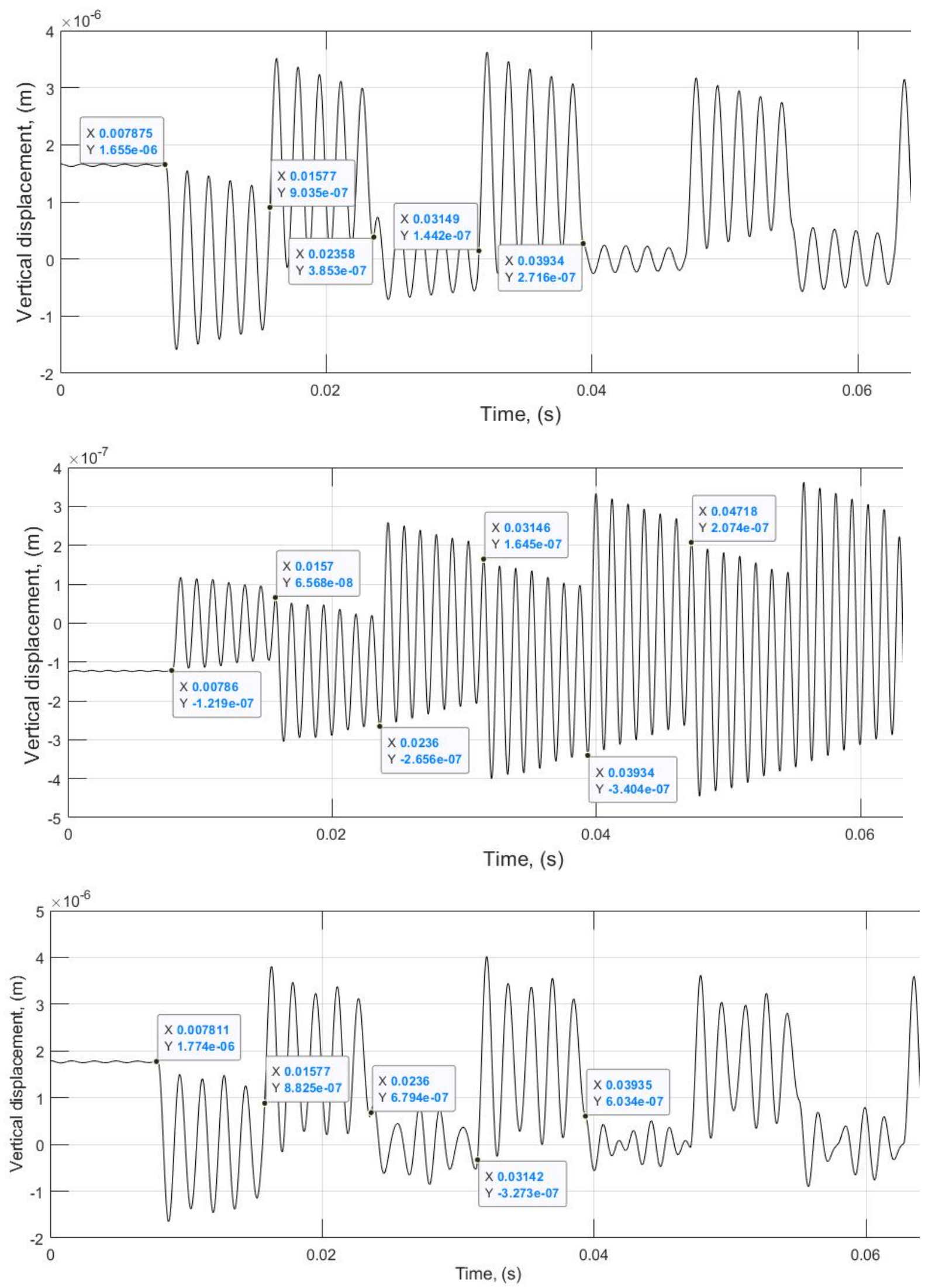

Fig. 9. Displacement the required values: a - displacement the machine spindle in the vertical direction (required value $\mathrm{x}_{1}$ ); $\mathrm{b}$-displacement the machine table in the vertical direction (required value $\mathrm{x}_{3}$ ); $\mathrm{c}$ - mutual displacement of the table of machine and part in the vertical direction (required size $\mathrm{x}_{5}$ ) 


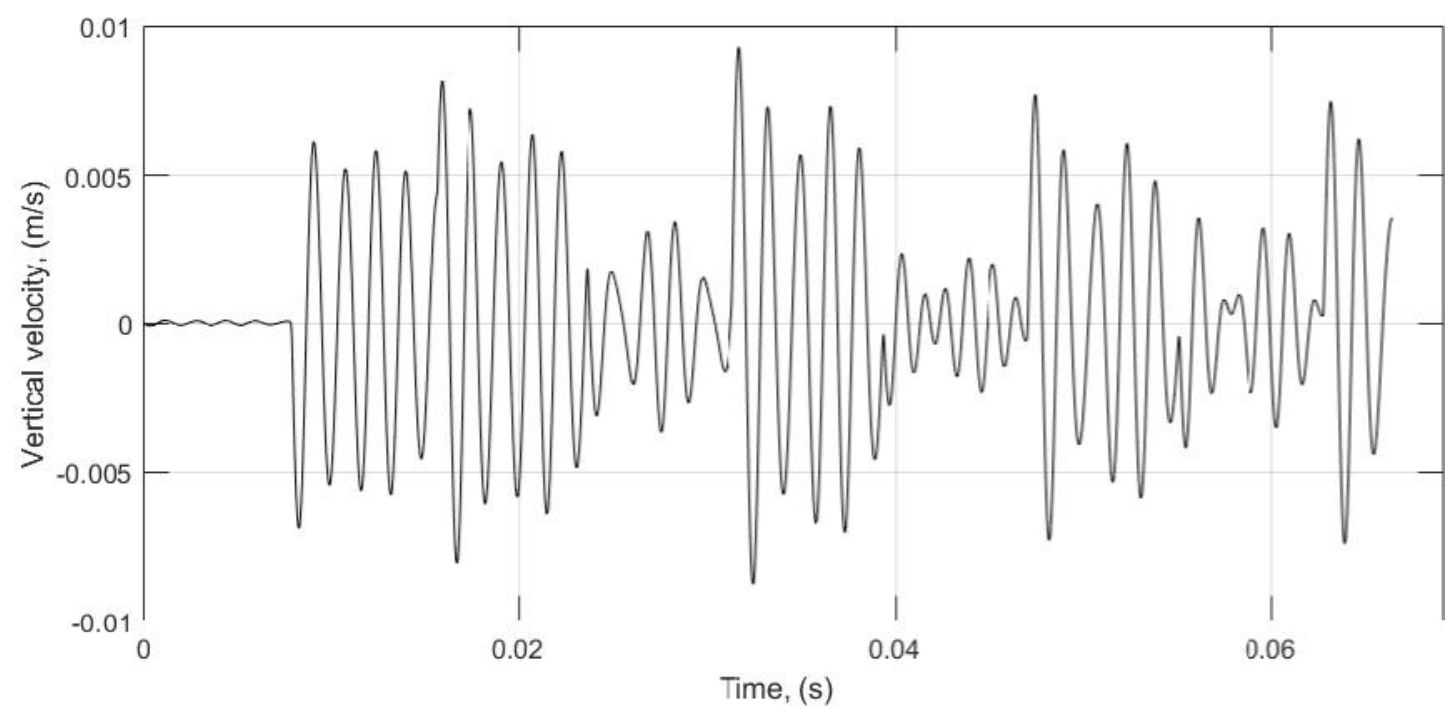

Fig. 10. Mutual velocity of the table of machine and part in the vertical direction

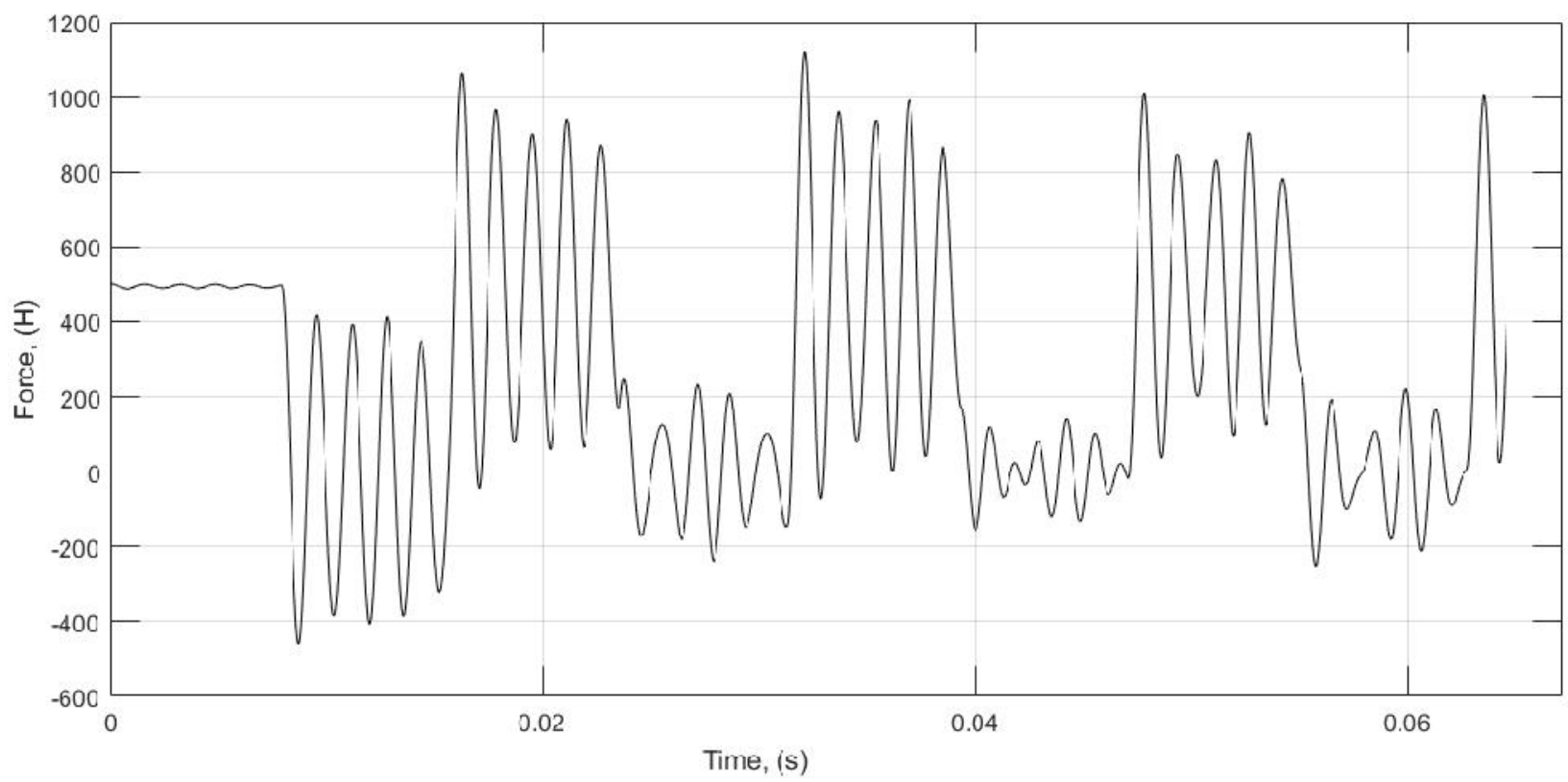

Fig. 11. The interaction force between part and tool

\section{Conclusions}

The simulation model of dynamic processes of the machine elastic system during the frictional strengthening of machine parts' flat surfaces is developed in the work. To improve the quality parameters of the strengthened (reinforced) surface layer with a nanocrystalline structure, a tool-disk with a discontinuous (with grooves) working part is used, which leads to an increase in the of the system oscillating processes intensity. The obtained simulation model allows to determine the supports reactions of the table and the spindle unit, as well as to check the existence of dangerous loads on the parts of the elastic system units of the machine during strengthening (hardening).

\section{References}

[1] K.A. Yushchenko, et al., Inzheneriya poverhni [Surface engineering]. Kyiv, Ukraine: Naukova dumka Publ., 2007. [in Ukrainian].

[2] V.D. Evdokymov, L.P. Klymenko, and A.N. Evdokymova, Tekhnologiya uprochneniya mashynostroitelnych materialov [Hardening technology for engineering materials]. Odessa-Nykolaev, Ukraine: Yzd- 


\section{Simulation Modelling of Dynamic Processes Due Discontinuous Frictional Treatment of the ...}

vo NHHU im. Petra Mohyly, 2005. [in Russian].

[3] F. Mojtahedi, H. Shahverdi, and M.J. Torkamany, "Surface treatment of nano-structured steel with pulsed laser", Materials Physics and Mechanics, no. 17, pp. 17-21, 2013.

[4] S. Soundarapandian, and B. Dahotre Narendra, "Laser Surface Hardening", Steel Heat Treating Fundamentals and Processes, vol. 4A., pp. 476-502, 2013.

[5] X. Huang, at al., "Experimental research material characteristics effect on white layers formation in grinding of hardened steel", The International Journal of Advanced Manufacturing Technology, vol. 66, no. 9-12, pp. 1555-1561, 2013.

[6] V. Gurey, and I. Hurey, "The Effect of the Hardened Nanocrystalline Surface Layer on Durability of Guideways", in Lecture Notes in Mechanical Engineering. Advanced Manufacturing Processes. Selected Papers from the Grabchenko's International Conference on Advanced Manufacturing Processes (InterPartner-2019), vol. 1, pp. 63-72, 2020.

[7] I. Hurey, at al., "The research in to components of friction force tool part during friction hardening of plate steel faces", Advances in manufacturing science and technology, no. 3, pp. 56-64, 2014.

[8] V. Gurey, V. Korendiy, and P. Dmyterko, "Mathematical model of dynamic process during friction hardening of flat surface", Visnyk Natsionalnogo Universytetu Lvivska politehnika. Dynamika, mitsnist ta proektuvannia mashyn i pryladiv [Bulletin of the Lviv Polytechnic National University. Dynamics, strength and design of machines and devices], no. 788, pp. 79-85, 2014.

[9] I.M. Bat, G.Y. Dzhanelidze, A.S. Kelzon, Teoreticheskaya mekhanika v primerakh $i$ zadachakh [Theoretical mechanics in examples and problems]. St. Petersburg, Russia: Lan Publ., vol. 2, 2013. [in Russian].

[10] Ya.G. Panovko, Vvedeniye v teoriyu mekhanicheskikh kolebaniy [Introduction to the theory of mechanical oscillations]. Moskva, Russia: Nauka Publ., 1991. [in Russian]. 